\title{
ANÁliSE COMPARATIVA DA PRODUÇÃO DE LIPASE A PARTIR DE FRUTOS NECROSADOS
}

\author{
H. B. CARMINATI ${ }^{1}$, T. C. PIN ${ }^{1}$, M. O. D. MARTINS ${ }^{1}$ \\ ${ }^{1}$ Faculdades Integradas de Aracruz, Departamento de Engenharia Química \\ E-mail para contato: thaynara_coradini@hotmail.com
}

\begin{abstract}
RESUMO - Os processos industriais se deparam frequentemente com a necessidade de aperfeiçoar ou adequar suas técnicas a determinadas condições, nesse contexto a biotecnologia tem despertado grande interesse na indústria. Processos envolvendo alimentos, fármacos e até biocombustíveis possuem grande potencial para estudo via rota enzimática. Diante dessa realidade, o respectivo trabalho visa analisar a produção da enzima lipase a partir de fungos extraídos de cascas de frutos. O cultivo dos fungos foi realizado em isolamento direto seguido da repicagem, visando préselecionar os isolados. A partir desses isolados fúngicos, avaliou-se a atividade lipolítica e a classificação morfológica de cada exemplar. Foi possível observar que o fungo Aspergillus, oriundo do fruto de tomate apresentou melhor atividade lipolítica $(12,24 \mu \mathrm{molpNP} / \mathrm{min})$, sendo que os demais fungos apresentaram atividades variando de 5,35 a $10,01 \mu \mathrm{molpNP} / \mathrm{min}$, resultados avaliados como de bom potencial produtor da enzima.
\end{abstract}

\section{INTRODUÇÃO}

Diante de um cenário mundial marcado pela preocupação no esgotamento de matérias primas, o ramo de processos tem dedicado grandes esforços na busca de rotas alternativas para a fabricação de uma série de produtos. Mesmo que essa realidade de escassez esteja em um futuro não tão iminente, os centros de pesquisas e desenvolvimento de produtos investem recursos de uma forma exorbitante, na busca de rotas produtivas mais coerentes com o conceito de sustentabilidade. Rotas estas que proporcionem maiores rendimentos ou menores consumos de recursos (MASIERO e LOPES, 2008).

Essa preocupação com o processo produtivo tem conferido características favoráveis aos produtos em geral, tanto em sua composição, como em seu valor. Vários são os segmentos cujas rotas de processamento são constantemente marcadas por inovações; os ramos de alimentos, fármacos, cosméticos e biocombustíveis são os que mais se destacam.

A utilização de enzimas em processos industriais e laboratoriais ganhou ênfase em meados do século passado, sendo hoje alvo de intensos estudos em vários ramos. Tendo em vista essa constante procura por rotas alternativas de processos, o em questão busca estudar a produção de lipase, que seja afim do conceito de sustentabilidade. Os procedimentos a serem estudados 


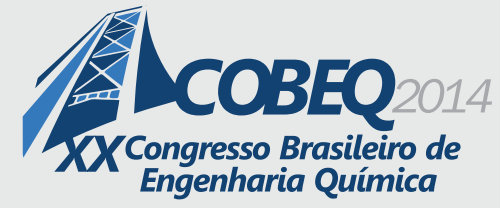

consistem em produção e seleção de fungos a partir de frutos necrosados, cuja capacidade para produção da enzima lipase sejam satisfatórias (MONTEIRO e SILVA, 2009).

\section{MATERIAIS E MÉTODOS}

A fim de garantir condições estéreis de crescimento dos microrganismos, a água, os meios de cultura e/ou substratos, vidrarias e utensílios laboratoriais foram esterilizados em autoclave vertical a $121^{\circ} \mathrm{C}$ (marca Quimis, modelo Q290-12), durante 20 minutos. Os isolados microbianos fora armazenados à temperatura de $5^{\circ} \mathrm{C}$, em tubos de cultura com o meio Sabouraud Dextrose Ágar conforme Menezes e Assis (2004). A recuperação ocorreu, sempre que necessária, repicando uma porção da colônia para o centro de placa de Petri com o meio de cultura Sabouraud Dextrose Ágar, seguindo-se incubação a $28^{\circ} \mathrm{C}$, por 5 dias, em estufa incubadora (DBO - Biotec BT424).

\subsection{Isolamento de Fungos com Potencial Lipolítico}

Para prover um meio favorável ao crescimento dos fungos de interesse foi utilizado o meio de cultura Sabouraud Dextrose Agar. Esse meio foi preparado de acordo com as especificações do fabricante $\left(65 \mathrm{~g}\right.$ de meio para $1 \mathrm{~L}$ de água destilada) e autoclavado a $121{ }^{\circ} \mathrm{C}$ por 20 minutos. Ao atingir a temperatura de $45{ }^{\circ} \mathrm{C}$, foram inseridos $10 \mathrm{mg} / \mathrm{L}$ de meio do antibiótico sulfato de estreptomicina (marca Micro-Química) e $10 \mathrm{mg} / \mathrm{L}$ de meio do antibiótico cloranfenicol (marca Sigma) visando atenuar o desenvolvimento de bactérias e actinomicetos.

Os fungos com potencial lipolítico foram isolados a partir de tecidos vegetais necrosados (banana, chuchu, mamão, tomate, pimentão, repolho e pera). O método para obtenção dos isolados foi o de isolamento direto, descrito por Menezes e Assis (2004), modificado por Rodrigues (2011), que consiste na transferência de esporos presentes na superfície dos frutos necrosados com a utilização de uma alça de repicagem descartável, ou com auxílio de um estilete flambado, usando o método de esgotamento em estrias, conforme Tortora (2005). Os esporos dos frutos foram transferidos para placas de Petri contendo $20 \mathrm{~mL}$ do meio Sabouraud Dextrose Agar, já preparado e as placas foram incubadas durante 10 dias à temperatura ambiente.

\subsection{Novos Fungos Isolados}

Após o período de incubação, as colônias morfologicamente diferentes foram repicadas, sucessivamente, para placas com o meio MMOS (meio mínimo mineral + óleo de soja), com a finalidade de aumentar a pressão de seleção por isolados fúngicos lipolíticos. 


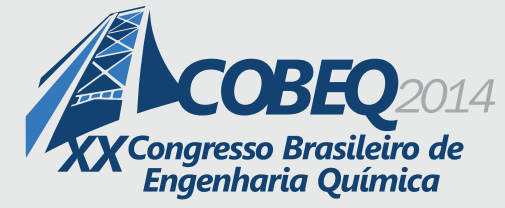

O MMOS teve a seguinte composição $\left(\mathrm{g} . \mathrm{L}^{-1}\right):\left(\mathrm{NH}_{4}\right)_{2} \mathrm{SO}_{4}(5,0), \mathrm{KH}_{2} \mathrm{PO}_{4}(0,9), \mathrm{NaCl}(1,0)$, $\mathrm{MgSO}_{4} \cdot 7 \mathrm{H}_{2} \mathrm{O}(0,3), \mathrm{Na}_{2} \mathrm{HPO}_{4}(6,2)$, ágar (15), solução de micronutrientes (1mL). O pH inicial foi de 6,5 (tampão fosfato $0,1 \mathrm{M}$ ). A solução de micronutrientes apresentou a seguinte composição (mg. $\mathrm{L}^{-1}$ ): $\mathrm{FeCl}_{3} \cdot 6 \mathrm{H}_{2} \mathrm{O}$ (2000), $\mathrm{ZnCl}_{2}$ (50), $\mathrm{CuCl}_{2} \cdot 2 \mathrm{H}_{2} \mathrm{O}$ (30), $\mathrm{MnCl}_{2} \cdot 2 \mathrm{H}_{2} \mathrm{O}$ (500), $\left(\mathrm{NH}_{4}\right)_{6} \cdot \mathrm{Mo}_{7} \mathrm{O}_{24} \cdot 4 \mathrm{H}_{2} \mathrm{O}(50), \mathrm{AlCl}_{3}(50), \mathrm{CoCl}_{3} \cdot 6 \mathrm{H}_{2} \mathrm{O}$ (2000), $\mathrm{HCl}$ concentrado (1mL). A solução foi agitada em agitador magnético (marca Quimis, modelo Q-261-2) por 20 minutos e transferida para frascos erlenmeyers de $1000 \mathrm{~mL}$ para autoclavagem por 20 minutos a $120^{\circ} \mathrm{C}$, seguindo-se o seu armazenamento a $5^{\circ} \mathrm{C}$, para posteriores utilizações. Foram acrescentados após resfriamento $50 \mathrm{mg}$ de sulfato de estreptomicina e $50 \mathrm{mg}$ de cloranfenicol, antibióticos contra bactérias e actinomicetos. Além destes, a este meio de cultura foi acrescentado o óleo de soja comercial (Liza) na concentração de $10 \%$ (v/v). O óleo de soja foi previamente emulsificado com Tween 80 , na concentração de $0,1 \%$, acrescentado de $1 \mathrm{~mL}$ de água esterilizada sob agitação em vortex por 5 minutos, visando otimizar a hidrólise dos lipídeos.

As colônias fúngicas que apresentaram crescimento no meio MMOS foram repicadas, sucessivamente, para placas de Petri com o meio de cultura Sabouraud, até o completo isolamento e purificação. Após cada repicagem os meios foram armazenados a $5{ }^{\circ} \mathrm{C}$. Este procedimento teve como função pré-selecionar isolados fúngicos com relação à produção de lipases.

\section{Caracterização dos isolados fúngicos}

Visando a caracterização morfológica e a identificação dos isolados fúngicos produtores de lipases ao nível de gênero (caracterização taxonômica), foram utilizados cultivos em meio de cultura Sabouraud, a $28^{\circ} \mathrm{C}$, durante 7 dias, visando a avaliação do aspecto das colônias (estruturas macroscópicas).

\subsection{Atividade Lipolítica de Isolados Fúngicos}

Nesta etapa foi avaliada a atividade lipolítica dos isolados fúngicos selecionados. Foi utilizada a fermentação submersa (FS), tendo como substrato o MMOS. Para o cultivo foram utilizados frascos Erlenmeyers de $125 \mathrm{~mL}$, com $50 \mathrm{~mL}$ do substrato por frasco. Cada frasco foi inoculado com $1 \mathrm{~mL}$ de suspensão de esporos fúngicos, na concentração de aproximadamente $10^{7}$ esporos $\cdot \mathrm{mL}^{-1}$, determinada em câmara de Neubauer. Os frascos foram incubados em agitação no shaker orbital de dupla ação (marca Marconi, modelo MA570), por 120 horas, a $150 \mathrm{rpm}$ e $30{ }^{\circ} \mathrm{C}$. O conteúdo de cada frasco foi então filtrado a vácuo com papel de filtro Whatman $n^{\circ} 4$. Do filtrado foram retiradas amostras de $1 \mathrm{~mL}$ e, transferidas para Eppendorfs estéreis, então centrifugados a $15000 \mathrm{xg}$ por 20 minutos a $4{ }^{\circ} \mathrm{C}$ e, posteriormente, os sobrenadantes foram coletados e destinados à determinação da atividade lipolítica extracelular. 
Os extratos enzimáticos obtidos na etapa anterior foram utilizados para a dosagem da atividade lipolítica em substrato à base de palmitato de para-nitrofenila (pNPP), conforme Winkler e Stuckmann (1979). Para tal foi adicionado 0,1 $\mathrm{mL}$ do extrato proteico a cada tubo de ensaio contendo $2,4 \mathrm{~mL}$ do substrato, submeteu-o à temperatura de $37^{\circ} \mathrm{C}$, durante 15 minutos, em banho-maria, após o seu pré-aquecimento à mesma temperatura. A reação ocorreu por ação da lipase presente no extrato protéico, que hidrolisa o palmitato de para-nitrofenila produzindo o paranitrofenol, um cromógeno amarelo, medido por espectrofotometria $(\lambda=410 \mathrm{~nm})$. Uma unidade de atividade enzimática (U) foi definida como a quantidade de enzima que promove a liberação de $1 \mu \mathrm{mol}$ de para-nitrofenol $\mathrm{min}^{-1}$, nas condições do teste (concentração do substrato, $\mathrm{pH}$, temperatura e tempo de reação), e calculada de acordo com a Equação 1 (ROWE e HOWARD, 2002).

$$
\text { Unidade de atividade lipolitica }=\frac{(A \cdot V)}{\left(\varepsilon \cdot T \cdot m_{p}\right)}
$$

Onde:

$A=$ absorbância $(\lambda=410 \mathrm{~nm})$;

$V=$ volume do ensaio em $\mathrm{mL}$;

$T=$ tempo em minutos;

$m_{p}=$ miligramas de proteína dosada pela determinação da curva padrão para o cálculo de proteínas totais; e

$\varepsilon=$ coeficiente de extinção molar de para-nitrofenol $\left(18,5 \mathrm{~mL} \mu \mathrm{mol}^{-1} \cdot \mathrm{cm}^{-1}\right)$.

\section{RESULTADOS}

\subsection{Isolamento e Classificação de Novos Fungos com Potencial Lipolítico}

Foram encontrados 6 isolados fúngicos, que foram repicados para placas de Petri contendo o meio MMOS enriquecido com óleo de soja. Tal procedimento foi realizado com intuito de aumentar a seleção por isolados fúngicos lipolíticos. A classificação dos fungos foi com base em características morfógicas apresentadas e de acordo com Barnet e Hunter (1986), Domsch, Gams e Anderson (1980) e Ellis (1997), sendo a classificação efetuada ao nível de gênero, podendo ser observada na Tabela 1 . 
Tabela 1 - Isolados fúngicos quanto à procedência, crescimento visual e classificação genérica.

\begin{tabular}{cccc}
\hline Isolado & Procedência & Crescimento Visual & $\begin{array}{c}\text { Classificação } \\
\text { genérica }\end{array}$ \\
\hline F01 & Fruto de chuchu & Positivo & Geotrichum \\
F02 & Fruto de pera & Positivo & Botrytis \\
F03 & Fruto de tomate & Positivo & Aspergillus \\
F04 & Fruto de banana & Positivo & Geotrichum \\
F05 & Fruto de tomate & Positivo & Geotrichum \\
\hline
\end{tabular}

Os fungos foram caracterizados de acordo com a morfologia das colônias (forma, textura e coloração) e a morfologia microscópica

\subsection{Atividade Lipolítica}

Foram feitas análises da atividade lipolítica em triplicata para os seis isolados encontrados. Na Tabela 2 encontram-se os resultados medianos desses isolados.

Tabela 2 - Resultado da atividade lipolítica dos isolados fúngicos.

\begin{tabular}{cccc}
\hline Isolado & $\begin{array}{c}\text { Classificação } \\
\text { genérica }\end{array}$ & $\begin{array}{c}\text { Média } \\
(\boldsymbol{\mu m o l p N P / m i n})\end{array}$ & Desvio $( \pm)$ \\
\hline F01 & Geotrichum & 10,01 & 5,95 \\
F02 & Botrytis & 8,88 & 1,53 \\
F03 & Aspergillus & 12,24 & 4,95 \\
F04 & Geotrichum & 5,35 & 0,27 \\
F05 & Geotrichum & 9,81 & 2,01 \\
\hline
\end{tabular}

Os resultados para fungos produtores de lipase, juntamente com o método do pNPP indicam a existência de atividade lipolítica extracelular. Os resultados obtidos permitem verificar também que o fungo F04, quando comparado com os demais, apresenta um valor menos significativo. Uma vez que o critério para seleção do fungo, foi eleger aquele com maior atividade lipolítica, o fungo F03 é o fungo selecionado, tendo em vista sua atividade lipolítica de $12,24 \mu \mathrm{molpNP} / \mathrm{min}$.

A seleção e isolamento de fungos com potencial para produção de lipase permitiu detectar que o fungo do gênero Aspergillus obteve o melhor resultado de atividade, mostrando a boa capacidade produtora da enzima. O resultado obtido está de acordo com o de Bajpai e Patil (1997), e Pinto (2003), que destacam a capacidade desse gênero fúngico em produzir enzimas extracelulares. Além disso, Dutra (2007) investigou as melhores condições para a produção de lipase Aspergillus, alcançando valores de atividades próximos ao encontrado neste trabalho. 


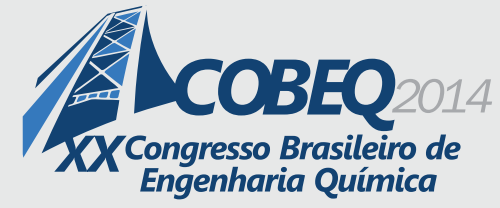

Em contrapartida, os autores Taboada (1999), Donatelli et al. (2002) e Fonseca et al. (2012) alcançaram uma atividade lipolítica para o fungo Geotrichum maior que a encontrada neste trabalho, mas isto se dá devido ao diferente método de obtenção da lipase, interferindo no seu resultado final. Já outros autores, como Lima Jr. (2009) e Rodrigues et al. (2009a, 2009b e 2009c), demonstraram ter havido boa correlação entre o método de difusão em ágar e com o método espectrofotométrico, no qual foi utilizado o pNPP, para a seleção de bactérias e fungos produtores de lipases, respectivamente.

\section{CONCLUSÕES}

Neste trabalho, foi possível verificar que as atividades lipolíticas podem ser aparentemente potencializadas e os resultados podem ser promissores, o que os credencia a futuras pesquisas visando sua utilização como biocatalisadores lipolíticos. Entretanto, a triagem de microrganismos produtores de enzimas é de grande importância para o descobrimento de enzimas mais estáveis e seletivas, podendo ser usadas futuramente para biocatálise e sínteses orgânicas.

O aperfeiçoamento no estudo realizado pode ser feito através de um planejamento experimental. Um delineamento fatorial é uma importante ferramenta que pode ser utilizada na busca pelas condições ótimas de operação, desde que sejam conhecidas as variáveis que influenciam o procedimento experimental, como temperatura e tempo de incubação, concentração de alguns componentes-chave, entre outros.

As enzimas lipolíticas tem atraído cada vez mais atenção por causa do seu potencial biotecnológico. Estas constituem o grupo mais importante de biocatalisadores para aplicações biotecnológicas. Neste trabalho o fungo F04 apresentou melhor atividade lipolítica e este é uma opção de continuidade para estudos futuros no ramo biotecnológico.

\section{REFERÊNCIAS}

BAJPAI, B.; PATIL, S. Induction of tanninacyl hidrolases (EC 3.1.1.20) activity insome members of fungiim perfecti. Enzyme and Microbial Technology, v. 20, p.612-614, 1997.

BARNET, H. C.; HUNTER, B. B. Illustrated genera of imperfect fungi. New York: Burg. Pub., 1986.

DOMSCH, K. H., GAMS, W.; ANDERSON, T. H. Compendium of soil fungi, v.1. London: Acad. Press, 1980.

DUTRA, J. C. V. Produção de lipase por Aspergillus niger 11 T53A14 através de fermentação em estado sólido para a síntese de biodiesel. Tese (Doutorado em Engenharia Química). Universidade Estadual do Rio de Janeiro: Rio de Janeiro, 2007. 


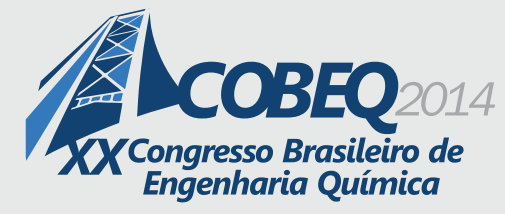

DONATELLI A. L. S., MOREIRA V. M., VASCONCELLOS, V. M., HIRATA D. B., ROQUE A. C. M., LUIZ J. H. H. Estudo da separação da lipase produzida por Geotrichum candidum por precipitação com diferentes solventes e por cromatografia. $25^{\circ}$ Reunião Anual da Sociedade Brasileira de Química. SBQ: Poços de Caldas, 2002.

ELLIS, M. B. More dematiaceous Hyphomycetes. Survey Common Health Mycology Institute: Kew, 1997.

FONSECA M. A., GONÇALVES J. F., RAMOS E. Z., HIRATA D. B., MENDES A. A., PEREIRA E. B. Aplicação da lipase produzida pelo fungo Geotrichum candidum na síntese de ésteres. Seminário de Iniciação Científica da UNIFAL, Alfenas: 2012.

LIMA JUNIOR, A.F. Biodegradação e atividade lipolítica em resíduos oleosos derivados do saneamento ambiental. Dissertação (Mestrado em Engenharia Ambiental). Universidade Federal do Espírito Santo: Vitória, 2009

MASIERO, G,; LOPES, H. Etanol e biodiesel como recursos energéticos alternativos: perspectivas da América Latina e da Ásia. Rev. bras. polít. int. 51 (2): 60-79, 2008.

MENEZES, M.; ASSIS, S. M. P. Guia prático para fungos fitopatogênicos. Imprensa Universitária da Universidade Federal Rural de Pernambuco: Recife, 2004.

MONTEIRO, V. N.; SILVA, R. N. Aplicações Industriais da Biotecnologia Enzimática. Rev. proc. Químicos. Jan./Jun. 2009.

PINTO, G. A. S. Produção de Tanase por Aspergillus niger. 213f. 2003. Tese (Doutorado em Processos Bioquímicos). Universidade Federal do Rio Janeiro: Rio de Janeiro, 2003.

RODRIGUES, C. Seleção de fungos produtores de lipases a partir de resíduos oleosos derivados do saneamento ambiental. Tese (Doutorado em Engenharia Ambiental). Universidade Federal do Espírito Santo: Vitória, 2011.

RODRIGUES, C.; CASSINI, S. T. A; GONÇALVES, R.F.; TSUKAMOTO, J.; BRITO, E. Isolamento de microrganismos de amostras ambientais visando sua utilização na geração de biodiesel. In: Congresso Brasileiro de Engenharia Sanitária e Ambiental. 25, 2009, Recife. Anais da ABES. 2009 a. 1 CD-ROM.

RODRIGUES, C.; CASSINI, S. T. A; GONÇALVES, R.F.; TSUKAMOTO, J.; BRITO, E. Seleção de microrganismos lipolíticos visando sua utilização na geração de biodiesel. In: Congresso Brasileiro de Engenharia Sanitária e Ambiental. 25, 2009, Recife. Anais da ABES. 2009 b. 1 CD-ROM.

RODRIGUES, C.; CASSINI, S. T. A; GONÇALVES, R.F.; TSUKAMOTO, J.; PEROVANO, T.G. Dosagem da atividade lipolítica de microrganismos de amostras ambientais visando sua utilização na geração de biodiesel. In: Congresso Brasileiro de Engenharia Sanitária e Ambiental. 25, 2009, Recife. Anais da ABES. 2009 c. 1 CD-ROM.

ROWE, L.; HOWARD, G. T. Grow thof Bacillus subtilis on polyurethane and the purification and characterization of a polyurethanase-lipase enzyme. Inter. Biodet. \& Biodeg., v. 50, n. 1, p. 33- 40, 2002. 
TABOADA O. W. M. Purificação de lipase de Geotrichum sp. por resina cromatográfica de interação hidrofóbica : modelagem, simulação e validação de parâmetros. Tese (Engenharia de Alimentos). Universidade Estadual de Campinas: Campinas, 1999.

TORTORA, G. J.; FUNKE, B. R.; CASE, C. L. Microbiologia. $8^{\text {a }}$ ed. Porto Alegre, Artmed, 2005.

WINKLER, U. K. E STUCKMANN, M. Glycogen, Hyaluronate, and some other polysaccharides greatly enhance the formation of exolipase by Serratia marcescens. J. Bacteriol. V. 3, p. 663-670, 1979. 